\title{
Night Temperature and Source-sink Effects on Growth, Leaf Carbon Exchange Rate, and Carbohydrate Accumulation in Bell Pepper Ovaries
}

\author{
Rebecca L. Darnell ${ }^{2}$, Nicacio Cruz-Huerta ${ }^{1}$, and Jeffrey G. Williamson \\ Horticultural Sciences Department, University of Florida, P.O. Box 110690, Gainesville, FL 32611
}

\begin{abstract}
AdDitional INDEX words. Capsicum annuum, defruiting, ovary swelling, photosynthesis
Abstract. Low night temperatures and/or high source-sink ratios increase ovary swelling and subsequent fruit malformation in many sweet peppers (Capsicum annuum), including bell pepper. Although this response has been correlated with increased ovary carbohydrate accumulation, evidence for this is limited. Furthermore, it is unknown how the combined effects of night temperature and source-sink ratio affect ovary carbohydrate accumulation and ovary swelling. The objectives of the present work were to determine night temperature and source-sink effects on ovary swelling, net carbon exchange rate (CER), and soluble sugar and starch concentrations in bell pepper ovaries at anthesis. Source-sink and temperature effects were tested by comparing fruiting (low source-sink ratio or high sink demand) with non-fruiting (high source-sink ratio or low sink demand) 'Legionnaire' bell pepper plants grown at 22/ $20^{\circ} \mathrm{C}$ [high night temperature (HNT)] or $22 / 12{ }^{\circ} \mathrm{C}$ [low night temperature (LNT)] day:night temperatures. Flowers that opened after imposition of the temperature and fruiting treatments were harvested at anthesis. Ovaries from harvested flowers were weighed and analyzed for non-structural carbohydrates. Leaf gas exchange measurements were performed every 3 days. Ovary fresh weight of flowers harvested at anthesis was highest in non-fruiting plants under LNT and lowest in plants grown under HNT regardless of fruiting status. Mean CER averaged over the experimental period was significantly higher in fruiting plants under HNT compared with all other treatments. There were no significant interactions between night temperature and fruiting status on ovary soluble sugar or starch concentrations. Low night temperature increased glucose, fructose, and starch concentration and decreased sucrose concentration in the ovary wall compared with HNT. There were no differences in soluble sugar or starch concentrations in the ovary wall between fruiting and non-fruiting plants. Thus, although both low temperature and high source-sink ratio (i.e., non-fruiting plants) resulted in ovary swelling, the mechanisms appear to differ. Whereas LNT effects on ovary swelling were associated with increased ovary carbohydrate accumulation, this association was not apparent when ovary swelling occurred in response to high source-sink ratios.
\end{abstract}

In pepper, like in all horticultural crops, quality is an important component of marketable yield. Fruit weight, shape, and uniformity are important quality components in pepper (Aloni et al., 1999; Kissinger et al., 2005; Lim et al., 2007; Navarro et al., 2002). In bell peppers, both shape and size are primarily determined at the preanthesis stage (Munting, 1974). Although genetics play a key role, several other factors also determine fruit shape and size during preanthesis, including temperature and carbohydrate availability (Aloni et al., 1999; Tomer et al., 1998).

Low night temperatures $\left(15^{\circ} \mathrm{C}\right.$ or lower $)$ negatively affect bell pepper fruit quality. One of the more striking effects of LNT on pepper flower development is an increase in ovary diameter without a concomitant increase in locule number, which results in "swollen" ovaries and malformed fruit (Aloni et al., 1999; Polowick and Sawhney, 1985; Shaked et al., 2004).

As the duration of LNT increases beyond $\approx 1$ week, both the percentage of ovaries that exhibit swelling (Aloni et al., 1999; Polowick and Sawhney, 1985) and the extent of ovary swelling (Cruz-Huerta et al., 2011) increase. Increased source-sink ratio also increases the proportion of swollen ovaries. Flower fresh weight $(\mathrm{FW})$ on defruited pepper plants was three to four times

Received for publication 13 May 2013. Accepted for publication 20 June 2013. ${ }^{1}$ Current address: Colegio de Postgraduados, Montecillo, Edo. de México, C.P. 56230 México.

${ }^{2}$ Corresponding author. E-mail: rld@ufl.edu. higher than flower FW on fruiting plants, which resulted in swollen ovaries and malformed fruit (Aloni et al., 1999).

The incidence of swollen ovaries in bell pepper resulting from either LNT or high source-sink ratio has also been correlated with increased ovary carbohydrate concentration (Aloni et al., 1999). Under LNT, pepper plants exhibit slower growth rates, resulting in decreased shoot dry weight (DW) compared with plants grown under higher night temperatures (Mercado et al., 1997). The decreased growth rate may be the result of decreased photosynthesis, because night temperatures below $15{ }^{\circ} \mathrm{C}$ may decrease ribulose-1,5-bisphosphate regeneration and $\mathrm{Pi}$ availability for recycling (Hendrickson et al., 2004a, 2004b) and/or activities of photosynthetic/carbohydrate metabolizing enzymes (Bertamini et al., 2005; Sundar and Reddy, 2000). Tropical crops, including pepper, are especially sensitive to LNT. Bhatt and Srinivasa-Rao (1993) reported that net $\mathrm{CO}_{2}$ exchange rates in pepper were higher at night temperatures of $22{ }^{\circ} \mathrm{C}$ compared with $17{ }^{\circ} \mathrm{C}$. However, night temperature effects on photosynthesis have not been studied in relation to ovary swelling in pepper. In some species such as cotton (Gossypium hirsutum) and bean (Phaseolus vulgaris), however, leaves developed under LNT may acclimate to such conditions, resulting in carbon exchange rates as high as in plants growing under higher temperatures (Singh et al., 2005; Wolfe and Kelly, 1992). It is unknown whether pepper leaves developed under LNT undergo acclimation and regain high photosynthetic rates. If so, then similar photosynthetic rates and slower growth rates under LNT may cause excess carbohydrate 
accumulation in floral ovaries, resulting in swelling and fruit deformation.

Vegetative growth and photosynthetic rates in pepper are also affected by source-sink ratios. In bell pepper, fruiting decreased vegetative growth rates (Bhatt and Srinivasa-Rao, 1989; Hall and Milthorpe, 1978) and increased leaf photosynthetic rates (Cruz-Huerta et al., 2005) compared with defruited plants. Defruiting, which increases the source-sink ratio, increased starch concentration in stems (Hall and Milthorpe, 1978) and the incidence of flower deformation and swollen ovaries (Aloni et al., 1999). In addition, the percentage of swollen flowers was inversely related to the number of growing fruit on the plant and directly proportional to the concentration of reducing sugars and starch in the flowers developed in those plants (Aloni et al., 1999). This suggests that although defruiting may decrease photosynthetic rates, the decreased carbohydrate production may not be sufficient to maintain an optimum source-sink balance. This may lead to greater assimilate accumulation in flower buds on defruited compared with fruiting plants, resulting in ovary swelling and fruit deformation.

Although ovary swelling is favored by LNT or increased source:sink ratio, the interaction between night temperature and source-sink modification on ovary carbohydrate accumulation and swelling has not been investigated. Thus, the hypothesis tested in the present experiment is that ovary swellingwhether resulting from LNT effects on photosynthesis and vegetative growth and/or resulting from fruiting effects on the source-sink ratio - results from increased non-structural carbohydrate accumulation in ovaries before and at anthesis. The objectives were to determine the interaction between night temperature and fruiting on 1) ovary swelling and vegetative growth; 2) leaf net CER and the photosynthetic acclimation ability of leaves to LNT; and 3) soluble sugar and starch concentrations in ovaries at anthesis.

\section{Materials and Methods}

Plant material and growing conditions. 'Legionnaire' bell pepper seeds were germinated in a mix of peatmoss, vermiculite, and dolomite limestone (Metro-Mix Ag-Lite Mix; Sun Gro Horticulture, Agawam, MA) and grown in 1.4- $\mathrm{m}^{2}$ growth chambers (E15; Conviron, Winnipeg, Manitoba, Canada) at $22 / 20{ }^{\circ} \mathrm{C}$ (day/night), 400 to $500 \mu \mathrm{mol} \cdot \mathrm{m}^{-2} \cdot \mathrm{s}^{-1}$ photosynthetic photon flux, and a 14-h photoperiod. Light was provided by fluorescent and incandescent lights at a wattage ratio of $4: 1$. At the sixth-leaf stage ( $\approx 50 \mathrm{~d}$ after sowing), seedlings were transplanted to 1.5 -L containers using the same growing media for germination and maintained in the growth chambers throughout the experiments. Plants were pruned to two axes, as previously described (Cruz-Huerta et al., 2011). Briefly, two shoots were allowed to grow at the first branching point to form the main stems. At each subsequent branching point on each of these main stems, the strongest shoot was allowed to develop and the second shoot was limited to the development of one flower and two leaves by pruning. Plants were fertigated as needed with the following nutrient solution (mM): $3.4 \mathrm{Ca}\left(\mathrm{NO}_{3}\right)_{2}, 1.8 \mathrm{KNO}_{3}, 1.6 \mathrm{KH}_{2} \mathrm{PO}_{4}, 0.3 \mathrm{KCl}, 2.7$ $\mathrm{MgSO}_{4}$, and $(\mu \mathrm{M}): 50.2 \mathrm{Fe}-\mathrm{EDTA}, 3.1 \mathrm{CuSO}_{4}, 14.6 \mathrm{MnSO}_{4}$, $64.8 \mathrm{H}_{3} \mathrm{BO}_{3}, 4.6 \mathrm{ZnSO}_{4}$, and $0.6 \mathrm{Na}_{2} \mathrm{MoO}_{4}$ (modified from Cruz-Huerta et al., 2005). Twenty-four 'Legionnaire' seedlings were selected $\approx 30 \mathrm{~d}$ after transplanting and flower buds from the main stem (first terminal flower) and the first node in the two axes were removed.

For the fruiting treatment (low source-sink ratio), flowers on nodes 2 and 3 were hand-pollinated, and one fruit per main axis was allowed to set, resulting in two fruit per plant. All subsequent flowers were removed as they opened. For the non-fruiting treatment (high source-sink ratio), no fruit were allowed to set and all flowers were removed as they opened. Approximately $10 \mathrm{~d}$ after petal fall occurred in the fruiting plants - when fruit enter the stage of rapid relative growth rate (Marcelis and Baan-Hofman-Eijer, 1995) - temperature treatments of $22 / 20{ }^{\circ} \mathrm{C}$ day/night (HNT) or $22 / 12{ }^{\circ} \mathrm{C}$ day/night (LNT) were imposed on both fruiting and non-fruiting plants, resulting in a two $\times$ two factorial [two night temperatures and two fruiting treatments (i.e., source-sink ratios)] with six single plant replications arranged in a completely random design. Temperatures were maintained by measuring leaf tissue temperatures at several points in the chambers with thermocouples connected to data loggers.

Flower ovary AND ORgan SAMPling. Flowers opened continuously after imposition of the temperature treatments and were harvested at or just before opening from both fruiting and non-fruiting plants throughout the 41-d experimental period. Harvested flowers were maintained on ice while ovaries were removed. Ovary FW, length, and diameter were recorded. After this, ovaries were separated into ovary wall and placenta using a scalpel. Fresh weights of ovary wall and placenta were recorded and parts were lyophilized (Model 10MR-TR; Virtis, Gardiner, NY) for 72 h. Samples were subsequently stored at $-20{ }^{\circ} \mathrm{C}$ in sealed containers until carbohydrate analysis. At the end of the experiment, organ DW, plant leaf area, and plant height were recorded. Additionally, a subsample $(n=6)$ of harvested ovaries from each treatment was dried and DW recorded.

Carbon exchange rate measurements. Gas exchange measurements on one to three of the most recently matured leaves per plant, which was the fourth or fifth from the apex, were performed using a portable photosynthesis system (LI6400; LI-COR, Lincoln, NE). Measurements were begun after imposition of temperature treatments and were done every $3 \mathrm{~d}$ during a 41-d period. This period of time ensured that several new leaves in each axis completely developed under the temperature treatments. Based on work by Choi and Gerber (1992), sweet pepper leaves take 4 to 5 weeks from the beginning of formation until full expansion. Measurements included net CER, stomatal conductance $\left(g_{\mathrm{S}}\right)$, intercellular $\mathrm{CO}_{2}$ concentration $(\mathrm{Ci})$, and leaf dark respiration (day and night). Net CER measurements were performed $\approx 6 \mathrm{~h}$ after the light period began. Respiration measurements during the day were performed 60 to $90 \mathrm{~s}$ after net CER measurements were completed by covering the top of the assimilation chamber with an opaque card and during the night before the dark period ended. Respiration measurements during the day were performed only twice at the beginning of the experiment [ 1 and $3 \mathrm{~d}$ after temperature treatments (DAT)] because no difference among treatments was found. Night respiration rates were measured at 13, 27, and 47 DAT.

Carbohydrate analysis. Carbohydrates were analyzed in ovaries as flowers were harvested throughout the experiment. For soluble sugar and starch analysis, samples were weighed and ground in liquid nitrogen. Samples (10 to $25 \mathrm{mg}$ ) were dissolved in $1 \mathrm{~mL} 80 \%$ ethanol, shaken at room temperature for 
$20 \mathrm{~min}$ in an orbital shaker at $200 \mathrm{rpm}$ (Model 361; Fisher Scientific, Pittsburgh, PA), and centrifuged at $1380 g_{\mathrm{n}}$ for $10 \mathrm{~min}$. The supernatant was removed, and the pellet was reextracted with ethanol. The supernatants of the two extractions were combined and total volume measured. The supernatants were cleared with activated charcoal to remove pigments and centrifuged at $13,250 \mathrm{~g}_{\mathrm{n}}$ for $5 \mathrm{~min}$. Soluble sugar recovery from samples was above $95 \%$, as determined by a ${ }^{14} \mathrm{C}$ external standard.

Soluble sugars were analyzed enzymatically using three enzyme systems (ES): 1) "ESA"—-hexokinase (EC 2.7.1.1, 0.05 units $/ \mu \mathrm{L})$ and glucose-6-phosphate dehydrogenase (EC 1.1.1.49, 0.08 units $/ \mu \mathrm{L}$ ) to measure glucose; 2) "ESB"-_ESA" and phosphogalactoisomerase (EC 5.3.1.9, 0.07 units $/ \mu \mathrm{L})$ to measure glucose and fructose; and 3) "ESC"__ "ESB" and invertase (EC 3.2.1.26, 0.80 units $/ \mu \mathrm{L}$ ) to measure glucose, fructose, and sucrose. The enzymes were diluted in $1 \% \mathrm{w} / \mathrm{v}$ bovine serum albumin (BSA), $1 \mathrm{M} \mathrm{HCl}$, and $40 \mathrm{~mm}$ tris(hydroxymethyl) aminomethane. For each ES, an aliquot of the cleared sample $(30 \mu \mathrm{L})$, the assay cocktail $(1 \mathrm{~mL})$, and the enzyme system $(10 \mu \mathrm{L})$ were mixed and incubated at room temperature for 60 to $90 \mathrm{~min}$ before reading absorbance at $339 \mathrm{~nm}$ in a spectrophotometer (ultraviolet-1800; Shimadzu Corp., Kyoto, Japan). The assay cocktail contained the following components: $170 \mathrm{~mm} \mathrm{~N}, \mathrm{~N}$-bis(2-hydroxyethyl)-2-aminoethanesulfonic acid, $65 \mathrm{~mm} \mathrm{KOH,} 15 \mathrm{~mm} \mathrm{MgCl}_{2}$, $1.5 \mathrm{~mm}$ EDTA, 2 mm nicotinamide adenine dinucleotide phosphate, $5 \mathrm{~mm}$ adenosine triphosphate, and $0.015 \% \mathrm{w} / \mathrm{v}$ BSA. Fructose and sucrose concentrations were determined by subtracting the appropriate ES values.

Sample pellets were analyzed for starch using amyloglucosidase (EC 3.2.1.3, 50 units/sample) and measuring resultant glucose equivalents. Pellets were boiled in $2 \mathrm{~mL} 0.2 \mathrm{~N} \mathrm{KOH}$ for $30 \mathrm{~min}$, then acidified with $1 \mathrm{~mL}$ of $1 \mathrm{M}$ acetic acid. After cooling, $1 \mathrm{~mL}$ of dialyzed amyloglucosidase solution (50 units/ $\mathrm{mL}$ in $0.2 \mathrm{M}$ calcium acetate buffer, $\mathrm{pH} 4.5$ ) was added and samples were incubated for $18 \mathrm{~h}$ at $37^{\circ} \mathrm{C}$. Volume was recorded and the digest was centrifuged for $10 \mathrm{~min}$ at $1975 \mathrm{~g}_{\mathrm{n}}$. An aliquot of the supernatant was removed and glucose was quantified. Percent recovery, as estimated using a ${ }^{14} \mathrm{C}$ external standard, was above $95 \%$.

Data Analysis. Data were analyzed using SAS (Version 9.2; SAS Institute, Cary, NC). Net carbon exchange rates during the day were analyzed as a two $\times$ two factorial (night temperature $\times$ fruiting status) with repeated measures over time using a completely randomized block design with six replications. The subject for repeated measures was the individual plant. Data from the two measurement dates for day respiration were pooled and analyzed as a two $\times$ two factorial, whereas night respiration data were analyzed as a factorial with repeated measures over time. Ovary size measurements, ovary carbohydrates, and final organ DW were analyzed as a two $\times$ two factorial using a completely randomized block design with six replications.

\section{Results}

Ovary SIZE. Ovary FW was highest in non-fruiting plants under LNT and lowest in plants grown under HNT regardless of fruiting status (Table 1). Ovary FW in non-fruiting plants under LNT averaged $\approx 185 \mathrm{mg}$, whereas ovary FW in plants grown under HNT averaged $\approx 120 \mathrm{mg}$ regardless of fruiting status. Ovary FW in fruiting plants under LNT was intermediate,
Table 1. Night temperature and fruiting effects on ovary fresh weight in 'Legionnaire' bell pepper flowers harvested at anthesis.

\begin{tabular}{lcc}
\hline & \multicolumn{2}{c}{ Ovary fresh wt $(\mathrm{mg})^{\mathrm{z}}$} \\
\cline { 2 - 3 } Night temp $\left({ }^{\circ} \mathrm{C}\right)$ & Non-fruiting & Fruiting \\
\hline 12 & $184.9 \mathrm{a}^{\mathrm{y}}$ & $159.2 \mathrm{~b}$ \\
20 & $127.0 \mathrm{c}$ & $114.8 \mathrm{c}$
\end{tabular}

${ }^{\mathrm{z}}$ Non-fruiting = high source-sink ratio; fruiting = low source-sink ratio. ${ }^{y}$ Means in columns and rows followed by the same letter are not significantly different using least square means at $P \leq 0.05(\mathrm{n}=24)$.

averaging $\approx 160 \mathrm{mg}$. Ovary $\mathrm{FW}: \mathrm{DW}$ was significantly greater in plants grown under LNT compared with HNT (5.7 vs. 5.3, respectively; $P \leq 0.02$ ). Fruiting status did not affect the ratio and there was no significant interaction between night temperature and fruiting status.

Carbon exchange rates. There was a significant interaction between night temperature and fruiting status on CER. Mean CER averaged over the experimental period was significantly higher in fruiting plants under HNT compared with all other treatments (Table 2). Both $g_{\mathrm{S}}$ and $\mathrm{Ci}$ were higher in plants grown under HNT compared with LNT, but neither was significantly affected by fruiting status within a night temperature treatment.

The interaction between night temperature and fruiting status on CER was seen throughout most of the experimental period (Fig. 1), where CER of fruiting plants under HNT was significantly higher compared with non-fruiting plants under LNT from 16 DAT until the end of the experiment. There were no consistent differences in CER among non-fruiting plants under HNT or LNT or fruiting plants under LNT. However, CER was generally lower under LNT compared with HNT treatments throughout the experimental period. Stomatal conductance and $\mathrm{Ci}$ were significantly lower under LNT compared with HNT throughout the experimental period (Fig. 2A-B), reflecting differences in CER between the two night temperature treatments. Neither $g_{\mathrm{S}}$ nor $\mathrm{Ci}$ was significantly affected by fruiting (Fig. 2C-D).

Leaf respiration during the night was significantly lower under LNT compared with HNT, averaging 0.50 and 1.0 $\mu \mathrm{mol} \cdot \mathrm{m}^{-2} \cdot \mathrm{s}^{-1}$, respectively, and was unaffected by fruiting. Neither night temperature nor fruiting affected leaf respiration during the day, which averaged $2.0 \mu \mathrm{mol} \cdot \mathrm{m}^{-2} \cdot \mathrm{s}^{-1}$.

No significant night temperature effects were found on total plant or organ DW (Table 3). Plants growing under LNT were shorter as a result of fewer nodes compared with plants growing under HNT. On the other hand, fruiting significantly affected vegetative growth. Non-fruiting plants had higher leaf, stem, and root DW compared with fruiting plants. However, as a result of the obvious differences in fruit DW, total plant DW was unaffected by the presence/absence of fruit. No interactions between night temperature and fruiting vs. nonfruiting were found for any of the vegetative growth variables measured.

Carbohydrates. There were no significant interactions between night temperature and fruiting status on soluble sugar or starch concentrations. Low night temperature increased glucose, fructose, and starch concentration and decreased sucrose concentration in the ovary wall compared with HNT (Table 4). In contrast, soluble sugar and starch concentrations in the placenta were unaffected by night temperature. In general, there were no differences in soluble sugar or starch concentrations in the ovary wall or in placenta between fruiting 
Table 2. Night temperature and fruiting effects on carbon exchange rate (CER), stomatal conductance $\left(g_{\mathrm{S}}\right)$, and intercellular $\mathrm{CO}_{2}$ concentration $(\mathrm{Ci})$ in 'Legionnaire' bell pepper leaves.

\begin{tabular}{|c|c|c|c|c|c|c|}
\hline \multirow{2}{*}{$\begin{array}{l}\text { Night } \\
\text { temp }\left({ }^{\circ} \mathrm{C}\right)\end{array}$} & \multicolumn{2}{|c|}{$\operatorname{CER}^{\mathrm{z}}\left(\mu \mathrm{mol} \cdot \mathrm{m}^{-2} \cdot \mathrm{s}^{-1}\right)$} & \multicolumn{2}{|c|}{$g_{\mathrm{S}}\left(\mathrm{mol} \cdot \mathrm{m}^{-2} \cdot \mathrm{s}^{-1}\right)$} & \multicolumn{2}{|c|}{$\mathrm{Ci}\left(\mu \mathrm{mol} \cdot \mathrm{mol}^{-1}\right)$} \\
\hline & Non-fruiting ${ }^{y}$ & Fruiting & Non-fruiting & Fruiting & Non-fruiting & Fruiting \\
\hline 12 & $8.0 \mathrm{~b}^{\mathrm{x}}$ & $8.8 \mathrm{~b}$ & $0.10 \mathrm{c}$ & $0.11 \mathrm{bc}$ & $209.4 \mathrm{~b}$ & $214.4 \mathrm{~b}$ \\
\hline 20 & $9.4 \mathrm{~b}$ & $11.1 \mathrm{a}$ & $0.13 \mathrm{ab}$ & $0.16 \mathrm{a}$ & $235.5 \mathrm{a}$ & $239.8 \mathrm{a}$ \\
\hline
\end{tabular}

${ }^{\mathrm{z}}$ Gas exchange measurements were done $6 \mathrm{~h}$ after the day period began and every 3 to $4 \mathrm{~d}$ throughout the 41-d experiment on one to three of the most recently matured leaves per plant. Means were averaged over the experiment.

${ }^{\mathrm{y}}$ Non-fruiting $=$ high source-sink ratio; fruiting $=$ low source-sink ratio.

${ }^{x}$ Means within columns and rows for each variable followed by the same letter(s) are not significantly different using least square means at $P \leq 0.05(\mathrm{n}=36)$.

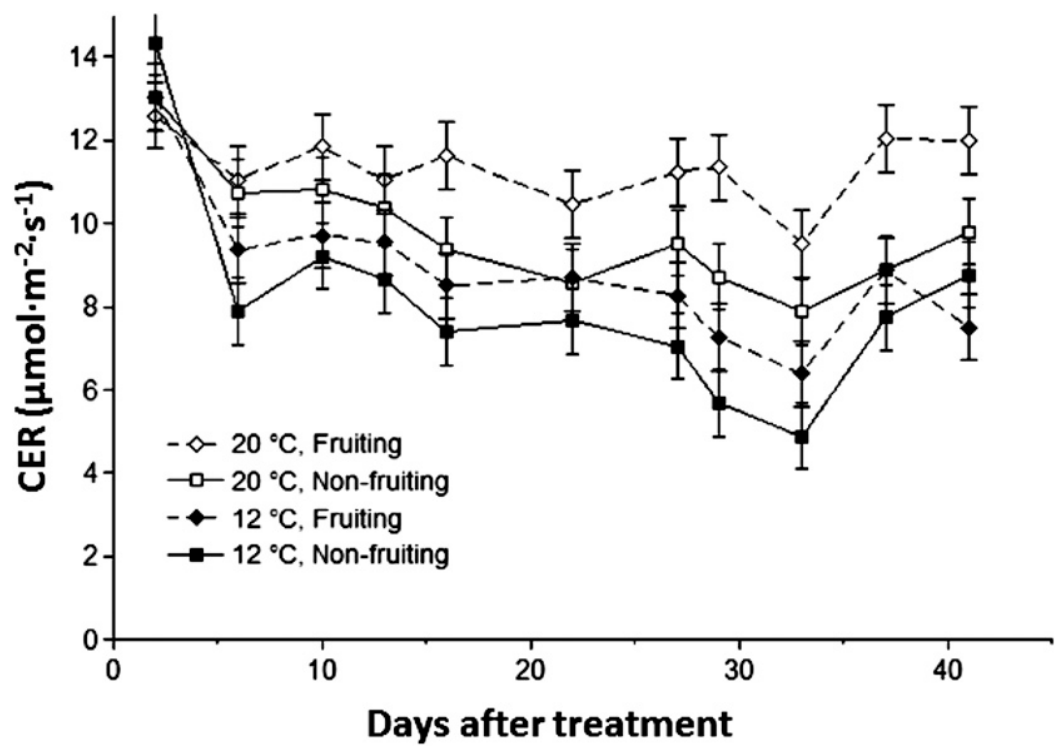

Fig. 1. Effect of night temperature and fruiting status on net carbon exchange rate (CER) in 'Legionnaire' bell pepper leaves. Measurements were done $6 \mathrm{~h}$ into the light period and over a 41-d period after the beginning of the treatments. Data are means $\pm \operatorname{SE}(n=6)$.

and non-fruiting plants with the exception of higher sucrose concentration in the placenta of fruiting plants.

Total content of reducing sugars and starch was also higher in the ovary wall of ovaries developed under LNT compared with ovaries in the HNT (Table 5). Sucrose content, however, was similar, because the increased DW under LNT (data not shown) was compensated by the decreased sucrose concentration. In the placenta, fructose and starch content was higher under LNT compared with HNT; however, sucrose and glucose contents were unaffected.

Soluble sugar content was higher in the ovary wall and placenta of non-fruiting compared with fruiting plants (Table 5). Starch content was also higher, although the increased starch in the ovary wall of non-fruiting compared with fruiting plants was not significant. No significant interaction was found between night temperature and fruiting vs. non-fruiting on carbohydrate content in the ovary wall or placenta.

\section{Discussion}

Low night temperatures combined with low sink demand (i.e., non-fruiting plants) increased ovary size $60 \%$ compared with ovaries developed under HNT and high sink demand (i.e., fruiting plants). Ovary swelling in bell pepper has been correlated with an increased concentration of reducing sugars and starch in the flower bud (Aloni et al., 1999). Because carbohydrate concentration and content ultimately depend on plant photosynthesis, we quantified leaf CER, organ DW accumulation, and ovary soluble sugar and starch concentrations in bell pepper grown under LNT vs. HNT and fruiting vs non-fruiting conditions.

Throughout the experiment, net CER of leaves developed under LNT in non-fruiting plants was lower compared with leaves developed on fruiting plants under HNT. Furthermore, net CER was generally lower in both LNT treatments compared with HNT treatments. This suggests that acclimation to LNT did not occur and contrasts with reports on cotton (Singh et al., 2005), guayule [Parthenium argentatum (Sundar and Reddy, 2000)], and bean (Wolfe and Kelly, 1992). In these species, leaves that developed under LNT exhibited CER similar to or greater than CER of leaves developed under warm night conditions. However, acclimation response appears to be species-specific, because other tropical and subtropical crops exhibited no acclimation to LNT (Venema et al., 1999; Wolfe, 1991). Furthermore, there is also genotypic variability within a species, because different tomato (Solanum lycopersicum) cultivars exhibited different acclimation responses to LNT (Van-de-Dijk and Maris, 1985).

The reduction in net CER in leaves developed under LNT in non-fruiting plants compared with those developed under HNT in fruiting plants appears to be the result of both stomatal and non-stomatal limitations. Both $g_{\mathrm{S}}$ and $\mathrm{Ci}$ were significantly lower under LNT compared with HNT, supporting the role of stomates in limiting CER in leaves developed under LNT compared with those developed under HNT. Reports of stomatal limitation to CER under LNT are common (Allen et al., 2000, and citations therein). A possible contribution of water deficit caused by reduced root hydraulic conductivity in LNT treatments was not assessed, but no signs of water deficit were observed during the study. Furthermore, CER measurements were taken $6 \mathrm{~h}$ after the light period began, likely giving sufficient time for soil and air temperatures to reach the day temperature before CER measurements and ameliorating LNT effects on hydraulic conductivity and the rate of stomatal opening. The effect of LNT on CER may also have been a symptom of chilling injury; however, morphological chilling symptoms were not observed in any of the plants grown under LNT. 

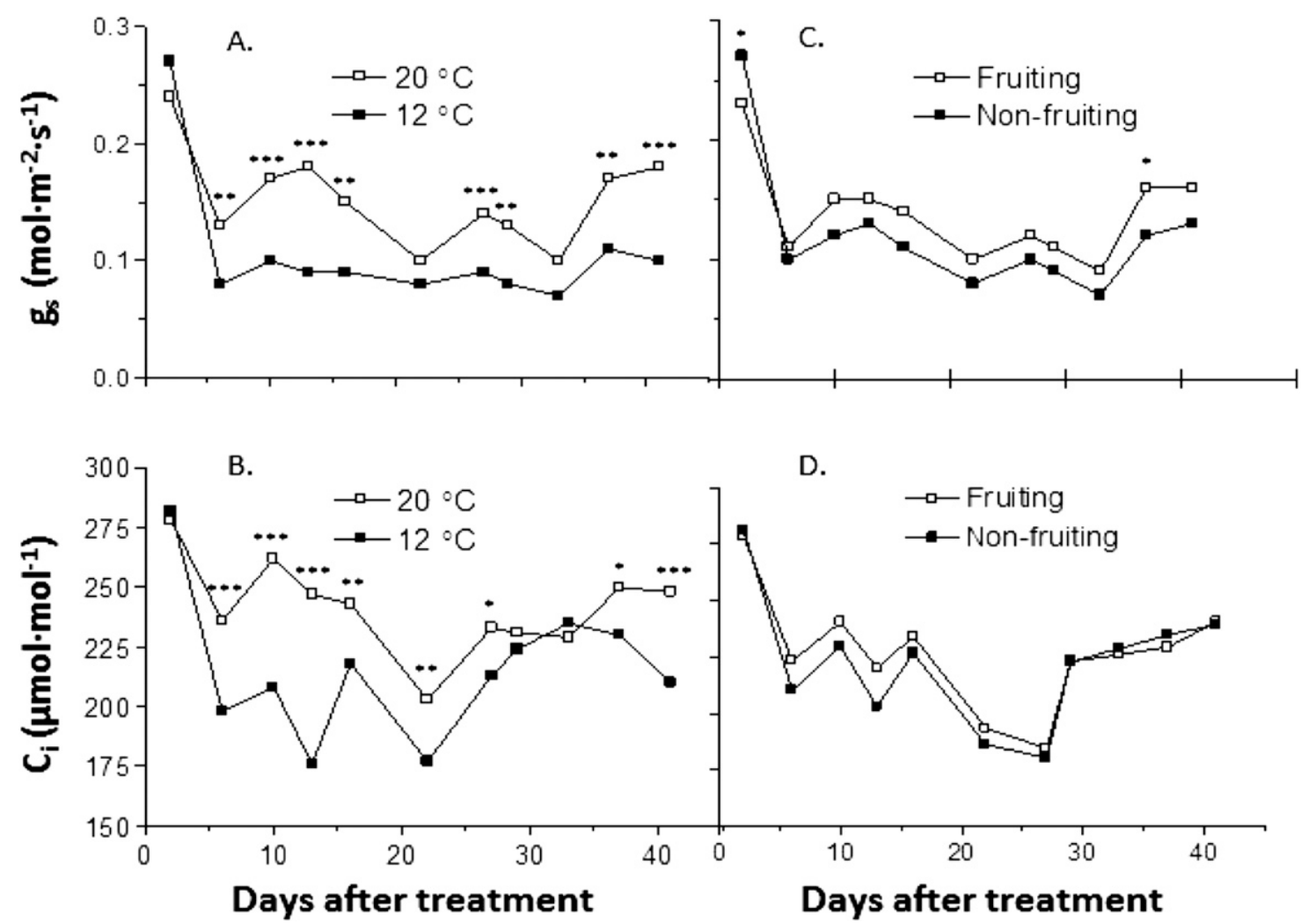

Fig. 2. Effect of night temperature (A-B) and fruiting status (C-D) on stomatal conductance $\left[g_{\mathrm{S}}(\mathbf{A}\right.$ and $\left.\mathbf{C})\right]$ and intracellular $\mathrm{CO}_{2}[\mathrm{Ci}(\mathbf{B}$ and $\mathbf{D})]$ in ' $\mathrm{Legionnaire}$ ' bell pepper leaves. Measurements were done $6 \mathrm{~h}$ into the light period and over a 41 -d period after the beginning of the treatments. Data for night temperature treatments were averaged across fruiting status. Data for fruiting treatments were averaged across night temperatures. *,**, *** Means between treatments within each measuring date were significantly different at $P \leq 0.05$ or 0.01 , or 0.001 , respectively $(\mathrm{n}=6)$.

Table 3. Main effects of night temperature and fruiting on growth of 'Legionnaire' bell pepper at the end of the experimental period.

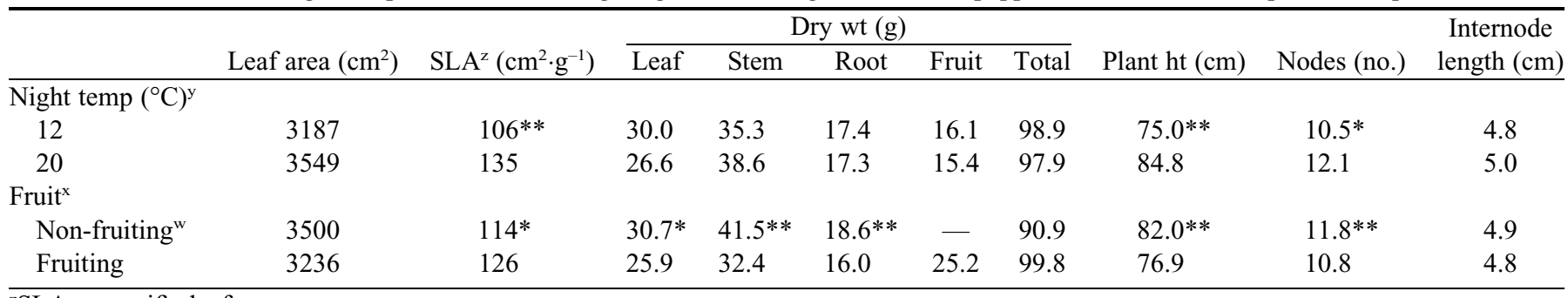

${ }^{\mathrm{z} S L A}=$ specific leaf area.

${ }^{\mathrm{y}}$ Data were averaged across fruiting treatments $(\mathrm{n}=12)$.

${ }^{x}$ Data were averaged across temperatures $(n=12)$.

${ }^{\mathrm{w}}$ Non-fruiting $=$ high source-sink ratio; fruiting $=$ low source-sink ratio.

$*$, ** Significant differences by $t$ test at $P \leq 0.05$ and 0.01 , respectively.

Although the reduction in $g_{\mathrm{S}}$ and $\mathrm{Ci}$ under LNT indicates a stomatal limitation to CER in non-fruiting plants under LNT, neither $g_{\mathrm{S}}$ nor $\mathrm{Ci}$ was affected by fruit removal, indicating the fruiting effect on CER was likely the result of non-stomatal rather than stomatal limitations. The most likely non-stomatal limitation is end-product inhibition (Pieters et al., 2001). Plants with low sink strength exhibit decreased sucrose synthesis as a result of low demand from the rest of the plant (Pieters et al., 2001). Low sucrose synthesis reduces the recycling of Pi to the chloroplast, adenosine triphosphate synthesis, and ribulose-1,5-bisphosphate regeneration and, therefore, photosynthesis (Pieters et al., 2001). Under sink-limited conditions, leaf starch concentration increases and specific leaf area decreases (Nederhoff et al., 1992). In addition, plant manipulations that cause sugars to accumulate can decrease the expression of photosynthetic genes and upregulate genes for carbon metabolism, increasing sucrose metabolism and starch accumulation (Koch, 1996), which may also explain the decrease in CER resulting from fruit removal.

Ovary carbohydrate accumulation was also affected by both night temperature and fruiting status. However, the effects of night temperature and fruiting status on carbohydrate accumulation as related to ovary size differed. Although non-fruiting plants under LNT exhibited the largest ovary size compared with all other treatments, only LNT, and not the fruiting status, 
Table 4. Main effects of night temperature and fruiting on soluble sugar and starch concentration in ovaries (ovary wall and placenta) of 'Legionnaire' bell pepper flowers harvested at anthesis. ${ }^{\mathrm{z}}$

\begin{tabular}{|c|c|c|c|c|c|c|c|c|}
\hline & \multicolumn{4}{|c|}{ Ovary wall $\left(\mu \mathrm{g} \cdot \mathrm{g}^{-1} \mathrm{DW}\right)^{\mathrm{y}}$} & \multicolumn{4}{|c|}{ Placenta $\left(\mu g \cdot g^{-1} D W\right)^{y}$} \\
\hline & Glu & Fru & Suc & Starch & Glu & Fru & Suc & Starch \\
\hline \multicolumn{9}{|l|}{ Night temp $\left({ }^{\circ} \mathrm{C}\right)^{\mathrm{x}}$} \\
\hline 12 & $31.9^{* *}$ & $31.9^{*}$ & $27.9^{*}$ & $56.9^{*}$ & 62.8 & 72.9 & 45.7 & 99.6 \\
\hline 20 & 26.2 & 26.3 & 35.6 & 44.8 & 61.1 & 65.8 & 50.5 & 87.4 \\
\hline \multicolumn{9}{|l|}{ Fruit $^{\mathrm{w}}$} \\
\hline Non-fruiting $^{v}$ & 29.0 & 30.1 & 31.4 & 46.6 & 63.4 & 68.6 & $44.2 *$ & 87.4 \\
\hline Fruiting & 29.1 & 28.2 & 32.0 & 55.1 & 60.5 & 70.1 & 52.1 & 99.6 \\
\hline
\end{tabular}

${ }^{\mathrm{z}}$ Flowers were harvested 24 to $29 \mathrm{~d}$ after treatments started.

${ }^{\mathrm{y}} \mathrm{Glu}=$ glucose; $\mathrm{Fru}=$ fructose; Suc $=$ sucrose.

${ }^{x}$ Means were averaged across fruiting treatments $(n=12)$.

${ }^{\mathrm{w}}$ Means were averaged across temperature treatments $(\mathrm{n}=12)$.

${ }^{\mathrm{N}}$ Non-fruiting $=$ high source-sink ratio; fruiting $=$ low source-sink ratio.

*, ** Significant differences by $t$ test at $P \leq 0.05$ and 0.01 , respectively.

$\mathrm{DW}=$ dry weight.

Table 5. Main effects of night temperature and fruiting on soluble sugar and starch content in ovaries (ovary wall and placenta) of 'Legionnaire' bell pepper flowers harvested at anthesis. ${ }^{\mathrm{z}}$

\begin{tabular}{lcccccccc}
\hline & \multicolumn{3}{c}{ Ovary wall content $(\mu \mathrm{g} / \text { flower })^{\mathrm{y}}$} & \multicolumn{3}{c}{ Placenta content $(\mu \mathrm{g} / \text { flower })^{\mathrm{y}}$} \\
\hline & Glu & Fru & Suc & Starch & Glu & Fru & Suc & Starch \\
Night temp $\left({ }^{\circ} \mathrm{C}\right)^{\mathrm{x}}$ & & & & & & & & \\
$\quad$ & $540^{* *}$ & $533^{* *}$ & 466 & $986^{*}$ & 976 & $1098^{*}$ & 658 & $1489^{*}$ \\
$\quad 20$ & 314 & 319 & 411 & 552 & 771 & 813 & 626 & 1071 \\
Fruit $^{\mathrm{w}}$ & & & & & & & & \\
$\quad$ Non-fruiting $^{\mathrm{v}}$ & $492^{*}$ & $501^{*}$ & $498^{*}$ & 844 & $1095^{* *}$ & $1158^{* *}$ & $729 *$ & $1494^{*}$ \\
Fruiting & 362 & 350 & 380 & 694 & 653 & 753 & 554 & 1066 \\
\hline
\end{tabular}

${ }^{\mathrm{z}}$ Flowers were harvested 24 to $29 \mathrm{~d}$ after treatments started.

${ }^{\mathrm{y}} \mathrm{Glu}=$ glucose; Fru $=$ fructose; Suc $=$ sucrose.

${ }^{x}$ Means were averaged across fruiting treatments $(n=12)$.

${ }^{\mathrm{w}}$ Means were averaged across temperature treatments $(\mathrm{n}=12)$.

${ }^{\mathrm{v}}$ Non-fruiting $=$ high source-sink ratio; fruiting $=$ low source-sink ratio.

$*$, ** Significant differences by $t$ test at $P \leq 0.05$ and 0.01 , respectively.

increased ovary carbohydrate concentration. The increased reducing sugar and starch concentration in ovaries developed under LNT compared with HNT may be the result of decreased night respiration at the lower temperature.

The lack of effect of the fruiting status on ovary carbohydrate concentration is in contrast to work by Aloni et al. (1999) who found increased carbohydrate concentrations in flower buds of non-fruiting compared with fruiting bell pepper. The fruiting plants used by Aloni et al. bore five developing fruit compared with two developing fruit used on fruiting plants in our work. Thus, although non-fruiting plants in our work exhibited an increase in the source-sink ratio compared with fruiting plants, the increase may have been sufficient only to increase ovary size and therefore carbohydrate content but not sufficient to increase carbohydrate concentration in ovaries.

We hypothesized that LNT and/or high source-sink ratio (as occurred in non-fruiting plants) would increase the incidence of swollen ovaries in pepper through a combination of maintaining net CER under conditions of reduced growth rates (LNT) and by reducing fruit demand for assimilates (high source-sink ratio). Both of these conditions would theoretically result in excess assimilate availability and increased incidence of swollen ovaries. We found, however, that although the combined effects of LNT and high source-sink ratio (non-fruiting plants) on ovary swelling appear to be additive, the mechanisms by which each factor increases ovary size may differ.
Ovary swelling caused by LNT was associated with increases in the concentrations and contents of reducing sugars and starch and a reduction in sucrose concentration in the ovary wall. This may result in an osmotic effect and an increase in water movement into ovaries, resulting in swollen ovaries. The significantly greater $\mathrm{FW}$ :DW ratio in plants grown under LNT compared with HNT supports this. Although LNT increased carbohydrate accumulation, the increase was not the result of maintenance of net CER in combination with a reduced growth rate under LNT. In contrast to night temperature effects, ovary swelling caused by a high sourcesink ratio (i.e., non-fruiting plants) was not associated with increased carbohydrate concentrations in the ovary, contrary to other reports. Our previous work (Darnell et al., 2012) found that high source-sink ratio increased cell number and cell size in the ovary wall compared with low source-sink ratio and that differences in night temperature exerted a much smaller effect on ovary anatomy. Thus, source-sink effects on ovary swelling appear to be more closely associated with changes in ovary anatomy with negligible effects resulting from carbohydrate concentration. To fully understand source-sink effects on ovary swelling in pepper, a range of source-sink ratios needs to be examined. Furthermore, the carbohydrate contribution from bell pepper fruit photosynthesis should be quantified because significant contributions from fruit photosynthesis would decrease sink demand for imported carbohydrates and therefore alter the source-sink ratio.

\section{Literature Cited}

Allen, D.J., K. Ratner, Y.E. Giller, E.E. Gussakovsky, Y. Shahak, and D.R. Ort. 2000. An overnight chill induces a delayed inhibition of photosynthesis at midday in mango. J. Expt. Bot. 51:1893-1902.

Aloni, B., E. Pressman, and L. Karni. 1999. The effect of fruit load, defoliation and night temperature on the morphology of pepper flowers and on fruit shape. Ann. Bot. (Lond.) 83:529-534.

Bertamini, M., K. Muthuchelian, M. Rubinigg, R. Zorer, and N. Nedunchezhian. 2005. Low-night temperature (LNT) induced changes of photosynthesis in grapevine (Vitis vinifera L.) plants. Plant Physiol. Biochem. 43:693-699.

Bhatt, R.M. and N.K. Srinivasa-Rao. 1989. Effect of deblossoming on photosynthesis and dry-matter distribution in bell pepper (Capsicum annuum L). Photosynthetica 23:466-471.

Bhatt, R.M. and N.K. Srinivasa-Rao. 1993. Response of bell pepper (Capsicum annuum $\mathrm{L}$ ) photosynthesis, growth, and flower and fruit setting to night temperature. Photosynthetica 28:127-132.

Choi, G.W. and J.M. Gerber. 1992. Studies on flower primordium differentiation of bell pepper (Capsicum annuum L.). HortScience 27:644 (abstr.). 
Cruz-Huerta, N., J. Ortiz-Cereceres, F. Sanchez-Del-Castillo, and M.C. Mendoza-Castillo. 2005. Biomasa e indices fisiológicos en chile morrón cultivado en altas densidades. Revista Fitotecnia Mexicana 28:287-293.

Cruz-Huerta, N., J.G. Williamson, and R.L. Darnell. 2011. Low night temperature increases ovary size in sweet pepper cultivars. HortScience 46:396-401.

Darnell, R.L., N. Cruz-Huerta, and J.G. Williamson. 2012. Night temperature and source-sink effects on overall growth, cell number, and cell size in bell pepper ovaries. Ann. Bot. (Lond.) 110:987-994.

Hall, A.J. and F.L. Milthorpe. 1978. Assimilate source-sink relationships in Capsicum annuum L. 3. Effects of fruit excision on photosynthesis and leaf and stem carbohydrates. Austral. J. Plant Physiol. 5:1-13.

Hendrickson, L., M.C. Ball, J.T. Wood, W.S. Chow, and R.T. Furbank. 2004a. Low temperature effects on photosynthesis and growth of grapevine. Plant Cell Environ. 27:795-809.

Hendrickson, L., W.S. Chow, and R.T. Furbank. 2004b. Low temperature effects on grapevine photosynthesis: The role of inorganic phosphate. Funct. Plant Biol. 31:789-801.

Kissinger, M., S. Tuvia-Alkalai, Y. Shalom, E. Fallik, Y. Elkind, M.A. Jenks, and M.S. Goodwin. 2005. Characterization of physiological and biochemical factors associated with postharvest water loss in ripe pepper fruit during storage. J. Amer. Soc. Hort. Sci. 130:735-741.

Koch, K.E. 1996. Carbohydrate-modulated gene expression in plants. Annu. Rev. Plant Physiol. Plant Mol. Biol. 47:509-540.

Lim, C.S., S.M. Kang, J.L. Cho, K.C. Gross, and A.B. Woolf. 2007. Bell pepper (Capsicum annuum L.) fruits are susceptible to chilling injury at the breaker stage of ripeness. HortScience 42:1659-1664.

Marcelis, L.F.M. and L.R. Baan-Hofman-Eijer. 1995. Growth analysis of sweet pepper fruits (Capsicum annuum L.). Acta Hort. 412:470 478.

Mercado, J.A., M.S. Reid, V. Valpuesta, and M.A. Quesada. 1997. Metabolic changes and susceptibility to chilling stress in Capsicum annuum plants grown at suboptimal temperature. Austral. J. Plant Physiol. 24:759-767.

Munting, A.J. 1974. Development of flower and fruit of Capsicum annuum L. Acta Botanica Neerlandica 23:415-432.
Navarro, J.M., C. Garrido, M. Carvajal, and V. Martinez. 2002. Yield and fruit quality of pepper plants under sulphate and chloride salinity. J. Hort. Sci. Biotechnol. 77:52-57.

Nederhoff, E.M., A.N.M. Dekoning, and A.A. Rijsdijk. 1992. Leaf deformation and fruit production of glasshouse grown tomato (Lycopersicon esculentum Mill) as affected by $\mathrm{CO}_{2}$, plant density and pruning. J. Hort. Sci. 67:411-420.

Pieters, A.J., M.J. Paul, and D.W. Lawlor. 2001. Low sink demand limits photosynthesis under Pi deficiency. J. Expt. Bot. 52:1083-1091.

Polowick, P.L. and V.K. Sawhney. 1985. Temperature effects on malefertility and flower and fruit-development in Capsicum annuum L. Sci. Hort. 25:117-127.

Shaked, R., K. Rosenfeld, and E. Pressman. 2004. The effect of low night temperatures on carbohydrates metabolism in developing pollen grains of pepper in relation to their number and functioning. Sci. Hort. 102:29-36.

Singh, B., L. Haley, J. Nightengale, W.H. Kang, C.H. Haigler, and A.S. Holaday. 2005. Long-term night chilling of cotton (Gossypium hirsutum) does not result in reduced $\mathrm{CO}_{2}$ assimilation. Funct. Plant Biol. 32:655-666.

Sundar, D. and A.R. Reddy. 2000. Low night temperature-induced changes in photosynthesis and rubber accumulation in guayule. Photosynthetica 38:421-427.

Tomer, E., H. Moshkovits, K. Rosenfeld, R. Shaked, M. Cohen, B. Aloni, and E. Pressman. 1998. Varietal differences in the susceptibility to pointed fruit malformation in tomatoes: Histological studies of the ovaries. Sci. Hort. 77:145-154.

Van-de-Dijk, S.J. and J.A. Maris. 1985. Differences between tomato genotypes in net photosynthesis and dark respiration under low lightintensity and low night temperatures. Euphytica 34:709-716.

Venema, J.H., F. Posthumus, and P.R. van Hasselt. 1999. Impact of suboptimal temperature on growth, photosynthesis, leaf pigments and carbohydrates of domestic and high-altitude wild Lycopersicon species. J. Plant Physiol. 155:711-718.

Wolfe, D.W. 1991. Low-temperature effects on early vegetative growth, leaf gas-exchange and water potential of chilling-sensitive and chilling-tolerant crop species. Ann. Bot. (Lond.) 67:205-212.

Wolfe, D.W. and M.O. Kelly. 1992. Photosynthesis of Phaseolus vulgaris in relation to leaf nitrogen and chlorophyll accumulation at low growth temperature. Photosynthetica 26:475-478. 